\title{
Caracterização de Onze Linhagens Puras de Guandu Selecionadas em São Carlos, SP Rodolfo Godoy ${ }^{1}$, Ângela Terumi Fushita ${ }^{2}$, Francisco H. Dübbern de Souza ${ }^{3}$
}

\begin{abstract}
RESUMO - Objetivou-se caracterizar morfologicamente e descrever o ciclo vegetativo de 11 linhagens de guandu previamente selecionadas por diversos critérios agronômicos e submetidas a processos de autofecundação, seleção e multiplicação, com vistas à obtenção de linhagens puras. A descrição foi efetuada com base em descritores internacionalmente aceitos para a espécie e concluiu-se que as 11 linhagens apresentaram características morfológicas distintas, pelas quais podem ser facilmente identificadas.
\end{abstract}

Palavras-chave: avaliação de forrageira, descrição botânica, Fabaceae, leguminosa forrageira tropical

\section{Description of Eleven Pigeon-pea Pure Lines Selected in São Carlos, SP}

\begin{abstract}
The purpose of this work was to morphologically characterize and describe the vegetative cycle of eleven previously selected pigeon-pea lines submitted to self pollination, selection and multiplication, to obtain pure lines. All descriptions were accomplished through the use of internationally accepted descriptors for the species and it was concluded that all eleven lines can be easily distinguished by means of their morphological traits.
\end{abstract}

Key Words: forage evaluation, botanical description, Fabaceae, tropical forage legume

\section{Introdução}

O guandu é utilizado em diversas regiões brasileiras para vários propósitos, porém sua mais frequiente utilização é na alimentação animal, tanto como pastagem exclusiva ou consorciada, como também na forma de forragem verde, de feno e como componente de mistura em silagens (Werner, 1979; Wutke, 1987).

Com o propósito de selecionar novas cultivares, Godoy et al. (1994) e Godoy et al. (1997) avaliaram agronomicamente duas coleções de germoplasma de guandu e verificaram que todos os acessos apresentavam, em graus variáveis, misturas mecânicas e segregação fenotípica. Por esta razão, os acessos selecionados foram submetidos a processos de autofecundação e seleção, visando à obtenção de linhagens puras. A partir de 1998, 17 dessas linhagens foram reavaliadas agronomicamente, para confirmação dos seus respectivos desempenhos agronômicos, caracterizadas morfologicamente e tiveram seu ciclo vegetativo descrito por Godoy et al. (2003). O objetivo foi a caracterização de mais 11 daquelas linhagens puras, das quais não se dispunha sementes em quantidade suficientes para serem incluídas na descrição anterior (Godoy et al., 2003). A descrição permitirá a agilização da solicitação de registro e proteção ao Ministério da Agricultura, Pecuária e Abastecimento, quando forem lançadas novas cultivares, bem como servirá para a correta identificação desses materiais no campo, no futuro, caso haja dúvidas.

\section{Material e Métodos}

A caracterização morfológica das linhagens puras e a descrição dos seus ciclos vegetativos foram feitas em um bloco de experimento de avaliação agronômica instalado na Embrapa Pecuária Sudeste, em São Carlos (SP), localizada na latitude -22,0, longitude 47,9 e $860 \mathrm{~m}$ de altitude. O experimento foi implantado em 20 de dezembro de 2002, com 14 tratamentos, 11 linhagens puras e três testemunhas, as cultivares comerciais Caqui, Anão e Fava Larga, já anteriormente descritas. As parcelas desse bloco foram constituídas por cinco linhas de $5 \mathrm{~m}$ de comprimento, com $0,5 \mathrm{~m}$ de espaçamento entre linhas e $0,25 \mathrm{~m}$ entre plantas.

Os descritores utilizados, adaptados de International Board for Plant Genetic Resources (IBPGR) e International Crop Research Institute for the Semi-Arid Tropics (ICRISAT) (1993), foram:

\footnotetext{
${ }^{1}$ Pesquisador da Embrapa Pecuária Sudeste, C.P. 339, 13500-970, São Carlos, SP. E.mail: godoy@cppse.embrapa.br.

2 Aluna do 5 o ano do curso de Ciências Biológicas da Universidade Federal de São Carlos e bolsista da Embrapa Pecuária Sudeste.

${ }^{3}$ Pesquisador da Embrapa Pecuária Sudeste, C.P. 339, 13500-970, São Carlos, SP. E.mail: fsouza@cppse.embrapa.br

* Trabalho parcialmente financiado pela Unipasto - Associação para o fomento à pesquisa de melhoramento de forrageiras tropicais.
} 
hábito de crescimento, altura de plantas $(\mathrm{cm})$ com $50 \%$ das plantas em florescimento, número de ramos primários, número de ramos secundários, espessura do caule $(\mathrm{mm})$ a $40 \mathrm{~cm}$ de altura, com $50 \%$ das plantas em florescimento (todos esses dados estimados pela média de cinco plantas), forma do folíolo, pilosidade do folíolo, cor básica (cor principal das pétalas) e cor secundária da flor, padrão das estrias da flor, padrão de florescimento, cor da vagem verde, forma e pilosidade da vagem, cor da vagem madura, padrão de coloração das sementes, cores básica e secundária das sementes, cor ao redor do hilo das sementes, largura do hilo, forma das sementes. Na descrição das cores foram obedecidos os padrões do British Colour Council (BBC) (1938), exceto para cores das vagens. Foram considerados eretos os genótipos cujos ramos primários faziam ângulo menor que $60^{\circ}$ com o caule e semiprostados aqueles cujos ângulos estavam entre 60 e $90^{\circ}$. As vagens verdes foram classificadas como púrpura, verde-claro, verdeclaro com estrias violeta, verde-claro com manchas violeta, violeta, violeta com estrias verde. As vagens maduras como marrom-claro, marrom com manchas púrpura, palha, palha claro, palha com manchas violeta escura, púrpura, violeta e violeta escura.

O padrão das estrias das flores foi descrito de acordo com a Figura 1, o padrão de coloração das sementes, conforme a Figura 2 e a forma das sementes, de acordo com a Figura 3.
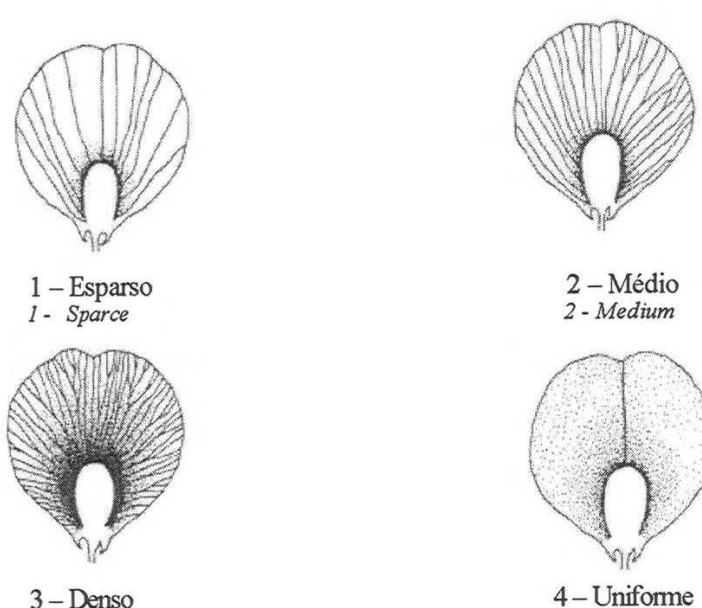

3-Dense



Figura 1 - Padrão das estrias: esparso, médio, denso ou uniforme.

Figure 1 - Patters of streaks: sparce, medium, dense or uniform coverage.

R. Bras. Zootec., v.33, n.6, p.2206-2213, 2004 (Supl. 3)

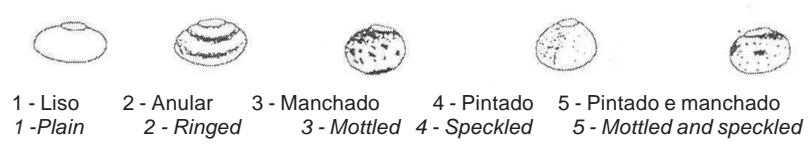

Figura 2 - Padrão de coloração das sementes: liso, anular, manchado, pintado ou pintado e manchado.

Figure 2 - Seed color pattern: plain, ringed, mottled, speckled, mottled and speckled.


1-Oval
1 - Oval

2-Redonda
2- Globular

3-Quadrada
3- Square

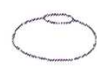

4-Alongada 4- Elongate

Figura 3 - Forma das sementes: oval, redonda, quadrada ou alongada.

Figure 3 - Seed shape: oval, globular, square or elongate.

Para a caracterização do ciclo vegetativo dos genótipos, simplificou-se a metodologia recomendada por IBPGR e ICRISAT (1993), tendo sido utilizados os seguintes parâmetros: dias da emergência ao início do florescimento, até $50 \%$ das plantas estarem em florescimento, até $100 \%$ plantas em florescimento, ao aparecimento das primeiras vagens e até $75 \%$ das vagens estarem maduras. Foi também anotado o período de florescimento em dias. Buscou-se utilizar apenas os descritores que pudessem servir à caracterização inequívoca de genótipos de guandu, sendo, portanto, excluídos aqueles mais influenciados pelo meio ambiente, de acordo com o proposto por Godoy et al. (2003).

\section{Resultados e Discussão}

Dos quatro possíveis hábitos de crescimento encontrados entre genótipos de guandu (IBPGR e ICRISAT, 1993), no presente trabalho, assim como em Godoy et al. (2003), apenas dois tipos foram encontrados entre as linhagens avaliadas. Os resultados são apresentados nas Tabelas 1 a 4 e, a seguir, são descritas as características observadas nesta coleção.

Hábito de crescimento: quatro linhagens (g8-95, g57-95, g137-99 e g142-95) apresentam hábito de crescimento semiprostrado, enquanto nas demais o hábito é ereto, revelando a predominância deste 
último tipo nos materiais selecionados, pois Godoy et al. (2003) encontraram plantas eretas em $89 \%$ dos genótipos avaliados.

Altura de plantas: para utilização como planta forrageira, seria desejável que as plantas fossem relativamente baixas, para facilitar o acesso dos animais e/ou cortes. Neste caso, embora a linhagem g57-95 tenha originalmente sido selecionada por ter baixa altura, com $50 \%$ de plantas em florescimento, nenhuma linhagem revelou possuir essa característica. Duas linhagens (g109-99 e g40-95) possuem altura entre 1,70 e 1,79 m, outras duas (g8-95 e g108-99), entre 1,80 e 1,89 me as linhagens g19m-95 e g138-99, entre 1,90 e $1,99 \mathrm{~m}$. As demais linhagens têm altura igual ou superior a 2 metros.

Número de ramos primários: no geral, foi superior ao número encontrado por Godoy et al. (2003), pois as linhagens descritas neste trabalho produzem plantas mais altas. Uma linhagem (g142-95) apresentou, em média, 14 ramos primários; uma (g109-99), 15; duas linhagens (g19m-95 e g57-95) apresentaram 17 ramos primários; duas (g137-99 e g149-99), 18; e duas (g40-95 e g186-98), 19 ramos. A linhagem g138-99 apresentou, em média, 23 ramos primários e as linhagens g8-95 e g109-99, 25.

Número de ramos secundários: a presença de número elevado de ramos secundários seria uma característica interessante para uma planta forrageira. Entretanto, poucas linhagens apresentaram essa característica. A linhagem g57-95 apresentou raros ramos secundários; as g8-95, g109-99 e g186-98 apresentaram dois e a g138-99, três ramos secundários. As demais linhagens não produziram ramos secundários.

Cor do caule: duas linhagens (g8-95 e g149-99) possuem caule verde-alface $861 / 2$; três (g19m-85, g57-95 e g142-96), caule verde-espinafre 960/2; g 186-88, verde-espinafre; 960/3 e g138-99 e g137-99, verde-samambaia 862/2. Três linhagens têm o caule estriado: g109-99, verde-salgueiro 000862/1 com estrias grená 1030/3; g40-95, verde-samambaia 862 com estrias púrpura-ameixa 934/3; e g108-99, vermelho-castanho 1030/3 com estrias verdeespinafre 960/2.

Espessura do caule: Todos os genótipos apresentam caules considerados por IBPGR e ICRISAT (1993) intermediários (5 a 13 mm), listados em ordem crescente de espessura: g109-99, g138-99, g108-99, g137-99, g142-95, g149-99, g186-98, g40-95, g57-95, g8-95 e g19m-95. Caules finos ou intermediários são

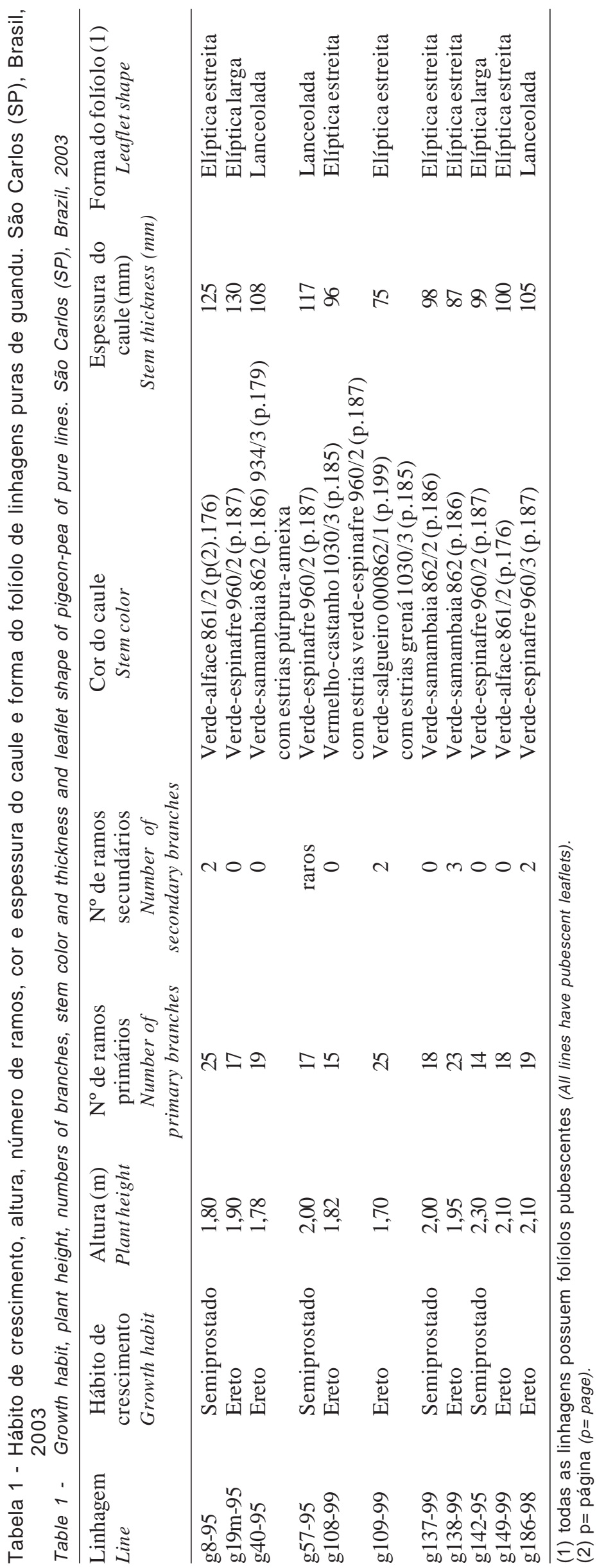


?] Tabela 2 - Caracterização das flores e do padrão de florescimento de linhagens puras de guandu. São Carlos (SP), Brasil, 2003

mable 2 - Flower color pattern and flowering pattern of pigeon-pea pure lines. São Carlos (SP), Brazil, 2003

\begin{tabular}{|c|c|c|c|c|c|c|}
\hline $\begin{array}{l}\text { Linhagem } \\
\text { Line }\end{array}$ & $\begin{array}{l}\text { Cor primária da flor } \\
\text { Primary flower color }\end{array}$ & \multicolumn{3}{|c|}{$\begin{array}{l}\text { Cor secundária da flor } \\
\text { Secondary flower color }\end{array}$} & $\begin{array}{l}\text { Padrão das } \\
\text { estrias } \\
\text { Streak pattern }\end{array}$ & $\begin{array}{c}\text { Padrão de } \\
\text { florescimento } \\
\text { Flowering pattern }\end{array}$ \\
\hline g8-95 & Amarelo-limão 4 (p.4) & \multicolumn{3}{|c|}{ Amarelo-cobalto 3/1 (p.3) com estrias rosa-magenta 27/1 (p(1).27) } & Médio & Indeterminado \\
\hline $\mathrm{g} 19 \mathrm{~m}-95$ & Amarelo-cromo 605 (p.144) & \multicolumn{3}{|c|}{ Vermelho-eritrito $27 / 1$ (p.190) } & Sem & Determinado \\
\hline $\mathrm{g} 40-95$ & Amarelo-cromo 605 (p.144) & \multicolumn{3}{|c|}{ Vermelho-rubi 827/2(p.171) } & Denso & Determinado \\
\hline g57-95 & Amarelo-cromo 605 (p.144) & \multicolumn{3}{|c|}{ Amarelo-bário 503 (p.131) } & Sem & Determinado \\
\hline g108-99 & Amarelo-cobalto 3 (p. 3) & \multicolumn{3}{|c|}{ Amarelo-mimosa 602/1 (p143) com estrias púrpura-rodamina 29 (p.29) } & Esparso & Indeterminado \\
\hline g109-99 & Amarelo-cromo 605/1 (p.144) & \multicolumn{3}{|c|}{ Amarelo-mimosa 602/1 (143) com estrias púrpura-beterraba 860/3 (p.173) } & Esparso & Indeterminado \\
\hline g137-99 & Amarelo-cromo 605 (p.144) & \multicolumn{3}{|c|}{ Vermelho-rubi 827 (p.171) } & Esparso & Determinado \\
\hline g138-99 & Amarelo-cromo 605 (p.144) & \multicolumn{3}{|c|}{ Vermelho-nastúrcio 14/2 (p.14) } & Esparso & Indeterminado \\
\hline g142-95 & Amarelo-limão 4 (p.4) & \multicolumn{3}{|c|}{ Amarelo-mimosa 602/1 (p.143) com estrias púrpura-petúnia 32/2 (p.32) } & Médio & Determinado \\
\hline g149-99 & Amarelo-cromo 605 (p.144) & \multicolumn{3}{|c|}{ Vermelho-rubi $827 / 2$ (p.171) } & Médio & Determinado \\
\hline g186-98 & Amarelo-cromo 605 (p.144) & \multicolumn{3}{|c|}{ Amarelo-cobalto 3/1 (p.3) com estrias rosa-magenta 27 (p.27) } & Uniforme & Indeterminado \\
\hline \multicolumn{7}{|c|}{$\begin{array}{l}\text { (1) } p=\text { página. } \\
\text { (1) } p=\text { page. }\end{array}$} \\
\hline \multicolumn{7}{|c|}{$\begin{array}{l}\text { Tabela } 3 \text { - Caracterização das vagens de linhagens puras selecionadas de guandu. São Carlos (SP), Brasil, } 2003 \\
\text { Table } 3 \text { - Pod color and shape of pigeon-pea pure lines. São Carlos (SP), Brazil, } 2003\end{array}$} \\
\hline Linhagem & \multirow{2}{*}{\multicolumn{2}{|c|}{$\begin{array}{l}\text { Cor das vagens verdes } \\
\text { Immature pod color }\end{array}$}} & Forma das vagens & Pilosidade das vagens & \multirow{2}{*}{\multicolumn{2}{|c|}{$\begin{array}{c}\text { Cor das vagens maduras } \\
\text { Mature pod color }\end{array}$}} \\
\hline Line & & & Pod shape & Pod hairiness & & \\
\hline g8-95 & \multicolumn{2}{|c|}{ Verde-claro com manchas violeta } & Achatada estreita & Lisa & \multicolumn{2}{|c|}{ Palha com manchas violeta escura } \\
\hline g19m-95 & \multicolumn{2}{|c|}{ Púrpura } & Achatada larga & Com pelos & \multicolumn{2}{|c|}{ Palha } \\
\hline g40-95 & \multicolumn{2}{|l|}{ Violeta } & Achatada larga & Com pelos & \multicolumn{2}{|l|}{ Palha } \\
\hline g57-95 & \multicolumn{2}{|l|}{ Verde-claro } & Achatada larga & Com pelos & \multicolumn{2}{|l|}{ Palha-claro } \\
\hline g108-99 & \multicolumn{2}{|l|}{ Violeta } & Achatada larga & Lisa & \multicolumn{2}{|l|}{ Violeta } \\
\hline g109-99 & \multicolumn{2}{|c|}{ Violeta com estrias verde } & Cilíndrica & Com pelos & \multicolumn{2}{|l|}{ Púrpura } \\
\hline g137-99 & \multicolumn{2}{|c|}{ Púrpura } & Achatada estreita & Com pelos & \multicolumn{2}{|c|}{ Violeta-escura } \\
\hline g138-99 & \multicolumn{2}{|c|}{ Verde-claro com estrias violeta } & Cilíndrica & Com pelos & \multicolumn{2}{|c|}{ Marrom com manchas púrpura } \\
\hline g142-95 & Verde com manchas $v$ & a escura & Achatada estreita & Lisa & Marrom-clar & \\
\hline g149-99 & Verde-claro com man & violeta & Cilíndrica & Lisa & Palha & \\
\hline g186-98 & Verde-claro com estri & oleta & Cilíndrica & Lisa & Palha & \\
\hline
\end{tabular}

Table 3 - Pod color and shape of pigeon-pea pure lines. São Carlos (SP), Brazil, 2003 
ग. Tabela 4 - Caracterização das sementes de linhagens puras selecionadas de guandu. São Carlos (SP), Brasil, 2003

[0 Table 4 - Seed characteristics of pigeon-pea pure lines. São Carlos (SP), Brazil, 2003

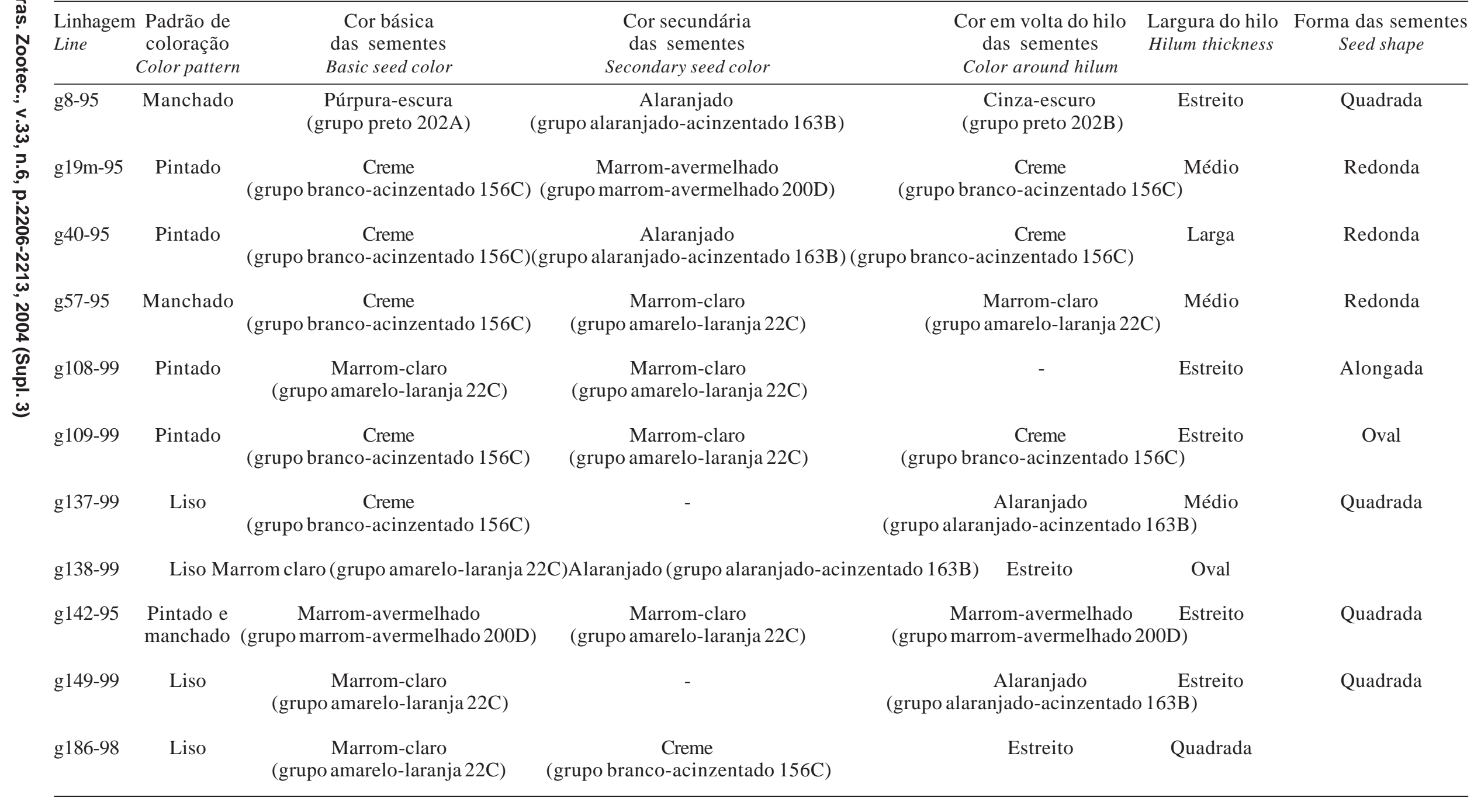


mais interessantes para plantas forrageiras e Godoy et al. (2003), avaliando outras linhagens selecionadas, encontraram poucas delas com caules grossos.

Forma do folíolo: a maior parte dos materiais (g8-95, g108-99, g109-99, g137-99, g138-99 e g149-99) tem o folíolo em forma elíptica estreita. As linhagens g19m-95 e g142-95 apresentam folíolos com forma elíptica larga e as g40-95, g57-95e g186-98, lanceolada. Todas as linhagens possuem folíolos pubescentes. Essas características, bem como as relativas à coloração de partes da planta, têm por função apenas a caracterização morfológica das linhagens.

Cor básica da flor: oito linhagens (g19m-95, g4095, g57-95, g137-99, g138-99, g149-99, g186-98 e g109-99) têm o amarelo-cromo 605 como cor básica da flor; uma apenas (g108-99) tem o amarelo-cobalto 3 e duas (g8-95 e g142-95) o amarelo-limão 4 como cor básica da flor.

Cor secundária da flor: três linhagens (g109-99, g142-95 e g108-99) apresentam o amarelo-mimosa 602/1 como cor secundária da flor, a primeira com estrias púrpura-beterraba 860/3, a segunda com estrias púrpura-petúnia $32 / 2$ e a terceira com estrias púrpura-rodamina 29. Três linhagens possuem o vermelho-rubi como cor secundária da flor, g137-99 (827) e g149-99 e g40-95 (827/2); duas outras, o amarelo-cobalto $3 / 1$ como cor secundária da flor, g8-95 e g186-98, a primeira com estrias rosa-magenta 27/1 e a segunda, 27.

Padrão das estrias: duas linhagens (g19m-95 e g57-95) não apresentam estrias; quatro possuem padrão denso, g108-99, g109-99, g137-99 e g138-99; três, g8-95, g142-95 e g19m-95, padrão médio; e duas, g108-99 e g109-99, esparso. Apenas a linhagem g40-95 apresenta padrão denso.

Padrão de florescimento: seis linhagens (g19m-95, g40-95, g57-95, g137-99, g142-95 e g149-99) têm padrão de florescimento determinado e as demais linhagens, indeterminado. A mesma proporção foi encontrada por Godoy et al. (2003). O florescimento de padrão determinado é mais vantajoso do ponto de vista de produção de sementes.

Cor da vagem: a classificação da cor da vagem, simplesmente como verde ou madura, não é suficiente para caracterizar uma linhagem. Assim, g19m-95 e g137-99 possuem vagens verdes púrpura, que se transformaram em vagens maduras palha e violetaescura, respectivamente. A linhagem g57-95 tem vagens verdes verde-claro que se transformaram em vagens maduras palha-claro, porém as linhagens g138-99 e g186-98 têm vagens verdes verde-claro com estrias violeta e vagens maduras marrom com manchas púrpura e palha, respectivamente, ao passo que as vagens verdes verde-claro com manchas violeta de g8-95 e g149-99 se transformam em vagens maduras de cor palha com manchas violetaescura no primeiro caso e palha, no segundo, ao passo que as vagens verdes verde com manchas violetaescura se transformam em vagens maduras marromclaro, no caso da linhagem g142-99. As linhagens g108-99, g40-95 e g109-99 têm vagens verdes violeta, no caso da última, com estrias púrpura, que se transformam em vagens maduras violeta, palha e púrpura, respectivamente.

Forma da vagem: quatrolinhagens (g109-99, g138-99, g149-99 e g186-98) apresentam vagens cilíndricas. As demais, achatadas e estreitas nos casos de g8-95, g137-99 e g142-95 largas para as demais linhagens.

Pilosidade da vagem: as linhagens g $19 \mathrm{~m}-95$, g40-95, g57-95, g109-99, g137-99 e g138-99 apresentam vagens pubescentes e as demais, vagens lisas.

Padrão de coloração das sementes: as linhagens g137-99, g138-99, g149-99 e g186-98 possuem o padrão de coloração de sementes liso, enquanto as linhagens g19m-95, g40-95, g108-99 e g109-99 têm esse padrão pintado. As linhagens g8-95 e g57-95 possuem sementes com padrão manchado e g142-95, pintado e manchado.

Cor básica das sementes: cinco linhagens, g19m-95, g40-95, g57-95, g109-99 e g137-99 possuem sementes com cor básica creme (grupo branco-acinzentado 156C) e quatro, marrom-claro (grupo amarelo-laranja 22C): g108-99, g138-99, g149-99 e g186-98. A linhagem g142-95 tem vagens marrom-avermelhado (grupo marrom-avermelhado 200D) e g8-95, púrpura-escura (grupo preto 202A).

Cor secundária das sementes: duas linhagens, g8-95 e g40-95 têm sementes com cor secundária alaranjado (do grupo alaranjado-acidentado163B) e três, marrom-claro (grupo amarelo-laranja 22C), g57-95, g109-99 e g142-95. A linhagem g19m-95 possui marrom-avermelhado (grupo marrom-avermelhado 200D) como cor secundária das sementes. As demais não apresentam cor secundária.

Características do hilo das sementes: quatro linhagens (g19m-95, g40-95, g109-99 e g186-98) apresentam a cor creme (grupo branco-acinzentado 156C) em volta do hilo das sementes, sendo o hilo, respectivamente, médio, largo e, das duas últimas, estreito. Três outras linhagens (g137-99, g138-99 e g149-99)

R. Bras. Zootec., v.33, n.6, p.2206-2213, 2004 (Supl. 3) 
Tabela 5 - Ciclo vegetativo de onze linhagens puras de guandu. São Carlos, SP, Brasil. 2003

Table 5 - Life cycle of eleven pigeon-pea pure lines São Carlos, SP, Brazil. 2003

\begin{tabular}{|c|c|c|c|c|c|c|}
\hline \multirow[t]{2}{*}{$\begin{array}{l}\text { Linhagem } \\
\text { Line }\end{array}$} & \multicolumn{6}{|c|}{$\begin{array}{l}\text { Dias da emergência ao (à) } \\
\text { Days from plant emergence to }\end{array}$} \\
\hline & $\begin{array}{l}\text { Início do } \\
\text { florescimento } \\
\text { Flowering } \\
\text { beginning }\end{array}$ & $\begin{array}{l}50 \% \text { plantas } \\
\text { florescimento } \\
50 \% \text { of plants } \\
\text { flowering }\end{array}$ & $\begin{array}{l}100 \% \text { plantas } \\
\text { florescimento } \\
100 \% \text { of plants } \\
\text { flowering }\end{array}$ & $\begin{array}{c}\text { Aparecimento } \\
\text { primeiras vagens } \\
\text { First pod } \\
\text { appearance }\end{array}$ & $\begin{array}{l}75 \% \text { de vagens } \\
\text { maduras } \\
75 \% \text { ripe pod }\end{array}$ & $\begin{array}{c}\text { Período de } \\
\text { florescimento } \\
\text { Flowering period }\end{array}$ \\
\hline g8-95 & 112 & 125 & 131 & 131 & 179 & 19 \\
\hline $\mathrm{g} 19 \mathrm{~m}-95$ & 117 & 122 & 131 & 131 & 172 & 14 \\
\hline g40-95 & 117 & 131 & 151 & 137 & 179 & 34 \\
\hline g57-95 & 118 & 137 & 147 & 144 & 186 & 29 \\
\hline g108-99 & 81 & 95 & 117 & 92 & 165 & 36 \\
\hline g109-99 & 125 & 149 & 161 & 152 & 193 & 36 \\
\hline g137-99 & 131 & 144 & 161 & 137 & 183 & 30 \\
\hline g138-99 & 125 & 144 & 155 & 144 & 155 & 30 \\
\hline g142-95 & 83 & 102 & 111 & 109 & 165 & 28 \\
\hline g149-99 & 139 & 139 & 181 & 161 & 202 & 42 \\
\hline g186-98 & 125 & 151 & 158 & 147 & 155 & 33 \\
\hline Média & 116 & 131 & 146 & 135 & 176 & 30 \\
\hline Means & & & & & & \\
\hline
\end{tabular}

apresentam a cor em volta do hilo alaranjada (grupo alaranjado-acinzentado 163B), sendo a primeira de hilo médio e as demais, estreito. As linhagens g57-95 e g108-99 têm a cor em volta do hilo marrom-claro (grupo amarelo-laranja 22C), com hilo médio e estreito, respectivamente. A linhagem g142-95 apresenta coloração em volta do hilo marrom-avermelhado (grupo marrom-avermelhado 200D) e g8-95, cinza escuro (grupo preto 202B), ambas de hilo considerados estreitos. No grupo de linhagens descrito por Godoy et al. (2003), a maioria possui coloração marrom-avermelhado.

Forma das sementes: cinco linhagens (g186-98, g137-99, g149-99, g142-95 e g8-95) apresentam sementes quadradas; três (g19m-95, g40-95 e g57-95), sementes redondas; duas (g109-99 e g138-99), sementes ovais; e g108-99, sementes alongadas.

Constam, na Tabela 5, as características do ciclo vegetativo das linhagens avaliadas. As linhagens de florescimento mais precoce foram g108-99 e g142-95, que iniciaram o florescimento 58 e 56 dias antes de g149-99, a linhagem mais tardia. Em ordem decrescente de precocidade estão: g8-95, g19m-95, g40-95, g57-95, g109-99, g138-99, g186-98, g137-99e g149-99. Para as características 50\% plantas em florescimento, $100 \%$ plantas em florescimento, aparecimento das primeiras vagens e $75 \%$ de vagens maduras, a ordem de precocidade foi muito semelhante à do início do florescimento. As linhagens g19m-95 e g8-95 apresentaram os florescimentos mais uniformes, com períodos de florescimentos de 14 e 19 dias, respectivamente, ao contrário de g149-99, que levou 42 dias em florescimento. É interessante notar que g19m-95 e g149-99 têm padrão de florescimento determinado, ao passo que na linhagem g8-95 o padrão é indeterminado, mostrando que essa característica não está relacionada à uniformidade de crescimento.

Essas observações são importantes do ponto de vista prático, pois normalmente para pastejo seria desejável plantas com florescimento tardio, mas uniforme, o que facilitaria a colheita de suas sementes, quando em sistemas de produção de sementes. Em outras situações, plantas de crescimento inicial rápido são desejáveis, não importando sua precocidade de florescimento, a não ser no caso também de produção de sementes.

Conforme constatado por Godoy et al. (2003), também para este grupo de linhagens, as características morfológicas utilizadas revelaram-se adequadas para a distinção das linhagens. Verificou-se ainda que a maior parte das linhagens pode ser individualmente distinguida apenas pelas características de suas sementes.

Godoy et al. (2003) sugeriram que, embora este tipo de trabalho em grandes coleções requeira elevado número de descritores, para coleções menores faz-se necessário buscar a simplificação dos descritores 
propostos por IBPGR e ICRISAT (1993), principalmente quanto à descrição das cores do caule, flores e sementes, uma vez que manuais de cores são de difícil obtenção e pouco práticos para utilização no campo. Os dados obtidos no presente trabalho corroboram essas observações, porém, decidiu-se manter os mesmos critérios para que todas as linhagens inicialmente selecionadas por Godoy et al. (1994) e Godoy et al. (1997) possam ser uniformemente caracterizadas.

\section{Conclusões}

Onze linhagens de guandu são descritas com base em características morfológicas distintas, facilmente identificáveis sob condições de campo.

Os descritores morfológicos utilizados são suficientes para caracterizar as linhagens e podem ser simplificados.

\section{Literatura Citada}

BRITISH COLOUR COUNCIL. Horticultural colour. London: The Royal Horticultural Society, 1938. 2v.

GODOY, R.; BATISTA, L.A.R.; NEGREIROS, G.F. Avaliação agronômica e seleção de germoplasma de guandu forrageiro (Cajanus cajan (L.) Millsp). Revista Brasileira de Zootecnia, v.23, n.5, p.742-749, 1994.
GODOY, R.; BATISTA, L.A.R.; NEGREIROS, G.F. Avaliação agronômica e seleção de germoplasma de guandu forrageiro (Cajanus cajan (L.) Millsp) proveniente da Índia. Revista Brasileira de Zootecnia, v.26, n.3, p.447-453, 1997.

GODOY, R.; BATISTA, L.A.R.; SOUZA, F.H.D., PRIMAVESI, A.C. Caracterização de linhagens puras selecionadas de guandu (Cajanus cajan (L.) Millsp). Revista Brasileira de Zootecnia, v.32, n.3, p.546-555, 2003.

INTERNATIONAL BOARD FOR PLANT GENETIC RESOURCES; INTERNATIONAL CROP RESEARCH INSTITUTE FOR THE SEMI ARID TROPICS. Descriptors for pigeon-pea (Cajanus cajan (L.) Millsp.) 1993, Rome. Rome: IBPGR; Patancheru, India: ICRISAT: 1993, 31p.

WERNER, J. C. O potencial do guandu (Cajanus cajan (L.) Millsp) como planta forrageira. Zootecnia, v.17, n.2, p.73$100,1979$.

WUTKE, E.B. Caracterização fenológica e avaliação agronômica de genótipos de guandu (Cajanus cajan (L.) Millsp. Piracicaba: Escola Superior de Agricultura "Luiz de Queiroz”, 1987. 164p. Dissertação (Mestrado em Fitotecnia) - Escola Superior de Agricultura "Luiz de Queiroz", 1987. 